\title{
Risk Assessment of Singeing Process for Skin-on Meat Chevon
}

\author{
Aremo John* and Omojola Babatunde \\ Department of Animal Science, University of Ibadan, Nigeria
}

Received: 眥 May 17, 2018; Published: 跙 May 25, 2018

*Corresponding author: Aremo John, Crystal JEM Agrofoods Concept, Ibadan, Nigeria

\begin{abstract}
Singed Skin-on meat from Red Sokoto Goat is favourably consumed in Nigeria, different singeing materials: kerosene, wood, scrap tyre, Liquefied Natural Gas (LNG) randomly assigned to singed Red Sokoto Goats to evaluate the quantity of singeing materials, duration of singeing, quantity of detergents and time take to clean up the carcass. Significant difference $(P<0.05)$ exist in the quantum of singeing materials and detergent used, the time required to remove soot and other particulate matter from singeing was least in LPG singed carcass (15.04 Minutes) while the duration for removing the physical and certain chemical contaminants from the carcass was significantly similar. Even though the quantity of tyre used was least, the duration of singeing using tyre was more than that of LPG. It was noted that the quantity of detergent in LPG and tyre singed carcass were highest while the quantity and duration of singeing were highest in wood and kerosene. Particulate matter emitted during singeing process poses threat to safety of life both on land and below water henceforth singeing should be replaced with other carcass dressing methods with strict policy.
\end{abstract}

Keywords: Skin-on Meat; Singeing; Particulate Matter; Safety; Tyre; Ogunfe; Ruminant Animals; Physical Contamination; Singed Carcass; Allegic Symptoms

\section{Introduction}

Chevon from Red Sokoto goat is a choiced meat available in most restaurants in Nigeria, it is popularly called 'ogunfe' in Yoruba speaking part of the country. Consumers relish it because of its distinct flavour which originates [1,2] from parietal region of the skin gland [3] and flavour contributing smoke compound derived from singeing. Singeing is the post-slaughter skin-on dressing of ruminant animals with open fire traditionally [4-6], using wood as fuel. Currently, different materials are employed in singeing owing to the relative scarcity of firewood. Spent engine oils Okiel [7]. Scrap tyre Obiri-Danso [6]. kerosene are used as fuel for dressing of carcass in our abattoir and during ceremonies and festive periods. Chemical and physical contamination are deposited from these materials during their combustion releasing their combustion particulate matters that are air toxics that and harmful to life both below water and on land and are deposited on the carcass, sometimes higher temperature during combustion tears the hide and opens up the carcass for further contamination. In the light of this prevailing situation in our abattoir, there is a need to explore the quantity and combustion time taken for the materials used to singe a Red Sokoto Goat of average weight of $12-15 \mathrm{~kg}$ economics of singeing process. LPG; liquefied petroleum gas From Table 1 , singeing duration of wood singed carcass was significantly highest $(\mathrm{P}<0.05) 38.67$ minutes followed by tyre singed carcass 35.53 minutes while LPG had the lowest time of 15.04 minutes However, highest quantity of wood $3.95 \mathrm{~kg}$ combusted to singe goat carcass followed by LPG $(1.63 \mathrm{~kg}),(0.64 \mathrm{~kg})$ in kerosene and least with scrap tyre $(0.41 \mathrm{~kg})$.The heat of combustion of gas (propane) is the highest of these four singeing materials with value range between $40.35-50.35 \mathrm{~mJ} / \mathrm{kg}$, the quantity of gas used for the study was $1.63 \mathrm{~g}$. Therefore, the total heat of combustion of gas is $78.81 \mathrm{MJ}$ in 15 minutes. Firewood heat for combustion ranges from $42.24 \mathrm{MJ} / \mathrm{kg}$ to $45.42 \mathrm{MJ} / \mathrm{kg}$ the quantity of firewood used was $3.95 \mathrm{~kg}$ the total heat of combustion dissipated on the carcasses from firewood is $81.42 \mathrm{MJ}$ in 38.68 minutes; this reveals that carcasses in this treatment were exposed to largest quantity of heat over a long period of time. The heat of combustion of kerosene is $20.09-21.14 \mathrm{MJ} / \mathrm{kg}$ an average of $28.05 \mathrm{MJ}$ was dissipated from $0.68 \mathrm{~kg}$ ( $\mathrm{ml}$ converted to $\mathrm{kg}$ ) in 31 minutes while for scrap tyre that 
has heat of combustion values ranging between $33-35 \mathrm{MJ} / \mathrm{kg}$ Juma [4] equivalents of $13.3 \mathrm{MJ}$ on carcasses in 36 minutes. This can be responsible for intact carcass in tyre singed carcass.

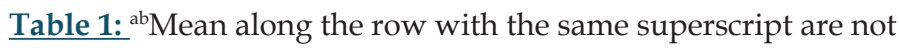
significantly differently $(\mathrm{P}>0.005)$.

\begin{tabular}{|c|c|c|c|c|c|}
\hline \multirow{2}{*}{ Parameter } & & Singeing & Materials & & SEM \\
\cline { 2 - 6 } & Kerosine & Wood & Tyre & LPG & \\
\hline $\begin{array}{c}\text { Quantity } \\
\text { of singeing } \\
\text { material (Kg) }\end{array}$ & $0.64^{\mathrm{c}}$ & $3.95^{\mathrm{a}}$ & $0.40^{\mathrm{c}}$ & $1.63^{\mathrm{b}}$ & 0.21 \\
\hline $\begin{array}{c}\text { Time for } \\
\text { singeing } \\
\text { (Mins) }\end{array}$ & $31.00^{\mathrm{ab}}$ & $38.67^{\mathrm{a}}$ & $35.53^{\mathrm{ab}}$ & $15.04^{\mathrm{c}}$ & 6.43 \\
\hline $\begin{array}{c}\text { Quantity of } \\
\text { soap (g) }\end{array}$ & $52.00^{\mathrm{b}}$ & $43.00^{\mathrm{c}}$ & $57.00^{\mathrm{a}}$ & $74.00^{\mathrm{a}}$ & 17.15 \\
\hline $\begin{array}{c}\text { Time for } \\
\text { washing } \\
\text { (Mins) }\end{array}$ & 6.69 & 6.50 & 8.00 & 8.00 & 0.10 \\
\hline
\end{tabular}

The average time for singeing Red Sokoto Goat in this study is between 15.04 minutes in LPG singed carcass to 38.67 minutes in wood carcass. Singeing using wood leads to the formation of various flavour-contributing smoke compounds, mainly phenols, the content of which increases as the wood combustion temperature rises.Therefore, larger body sized ruminants such as sheep and cattle will require a longer time if singeing irrespective of materials used will amount to more emission of air pollutants. Singeing is exothermic process which releases heat and particulate matters derived from both complete and incomplete combustion of the materials, Singeing emission includes liquid and solid components with different physical and chemical properties that is associated with health effect such as allegic symptoms asthma oxidative stress increase cardiovascular disorder airways inflammation it contains particulate matter toxic air pollutant which has both cooling and warming effect on the atmosphere which plays a central role in global climate IPCC 2007. Incomplete combustion releases different un-burned products asides $\mathrm{CO}_{2}$ and $\mathrm{H}_{2} \mathrm{O}$, these products includes $\mathrm{CO}, \mathrm{PAH}$, Soot particles and inorganic components like $\mathrm{HCl}, \mathrm{SO}_{2}, \mathrm{NO}_{2}$. CO serves as fuel used up during combustion, soots are fine carbon particles formed at high temperature breathing its tiny particles can cause coronary heart disease asthma and other respiratory illness, Unosson et al., 2013 reported that inhalation of the investigated sooty wood smoke caused an immediate increase in central arterial stiffness with reduced heart rate variability, co-emitted with soot is PAHs which are important component of organic matter combustion emission they are toxic, mutagenic and carcinogenic Kampa and Castana [5]. The result of carcass washing duration is in tandem with the quantity of soap used, there was no significant difference in the amount of soap (detergents) used to wash the carcasses after singeing but LPG singed carcass required more detergent of $75 \mathrm{~g}$ in 8 minutes of washing while $57 \mathrm{~g}$ was used for scrap tyre singed carcasses in 8 minutes, $52 \mathrm{~g}$ was used for kerosene singed carcasses in 6.69 minutes while $43 \mathrm{~g}$ was used for firewood singed carcasses in 6.50 minutes the quantity of the fraction of depositions which adheres to the hide is likely to be more on LPG singed carcass the ambient temperature for the processes ranged between 28-30 oC. Inorganic particles are ash forming matter which may be heavy metals together with soot particles from the singeing material are washed down to the body of water and thereby posing threat to aquatic ecosystem (Figure 1) [8].

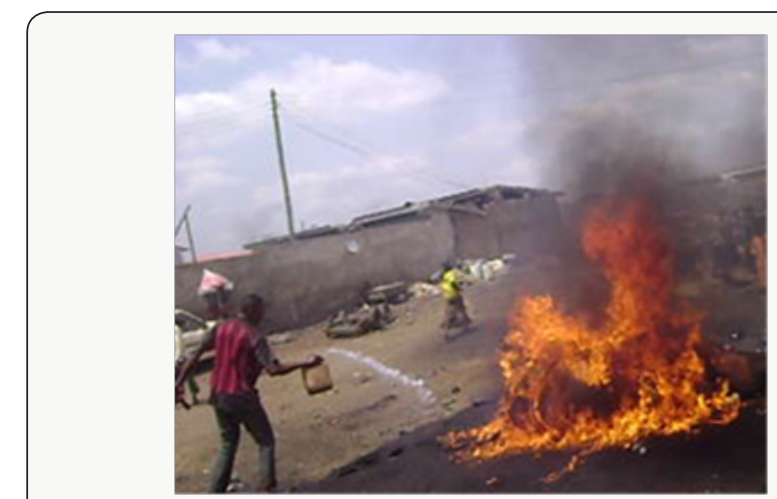

Figure 1: Singeing in Abattoir.

Source: Fieldwork.

\section{Conclusion}

The material with the least singeing time is liquefied petroleum gas which will optimise time of operation in abattoir, while it required the maximum quantity of detergent and washing time to remove soot from singed carcass and optimum quantity of singeing material while carcass singed with wood requires minimum detergent and duration of washing, However, Singeing process releases physical and chemical contaminants to the atmosphere and the practice cannot sustain good health and well-being of the citizens who relish the consumption of singed skin-on meat.

\section{References}

1. Brunekreef B, ST Holgate (2002) Air pollution and health lancet. 360(9341): 1233-1242.

2. Intergovernmental Panel on Climate Change (IPCC) (2007) The physical basis contribution of working group I to the fourth Assessment, Report of Intergovernmental panel on climate change climate change 2007.

3. Jenkinson McE D, PS Blackburn, R Proudfoot (1967) Seasonal changes in the skin glands of the goat. Br Vet J 123(12): 541-549.

4. Juma M, Z Koreňová, J Marks, J Annus, L Jelemensky (2006) Pyrolysis and Combustion of Scrap Tires Petroleum \& Coal 48 (1): 15-26.

5. Kampa ME, Castanas (2008) Human health effects of air pollution. Environmental pollution 151(2): 362-367.

6. Obiri Danso K, Hogarh JN, Antwi Agyei P (2008) Assessment of the contamination of singed hides from cattle and goats by heavy metals in Ghana. African Journal for Environmental Science and Technology 2(8): 217-221.

7. Okiel W, Ogunlesi M, Alabi F, Osiughwu B, Sojinrin A (2009) Determination of toxic metal concentrations in flame treated meat products, Ponmo. African Journal of Biochemistry Research 3(10): 332-339.

8. Unosson J, Blomberg A, Sandstrom T, Muala A, Boman C. (2013) Exposure to wood smoke increases arterial stiffness and decreases heart rate variability in humans. Part Fibre Toxicol 10(1): 20. 
This work is licensed under Creative Commons Attribution 4.0 License

Submission Link:

Submit Article

DOI: $10.32474 / C D V S .2018 .01 .000118$

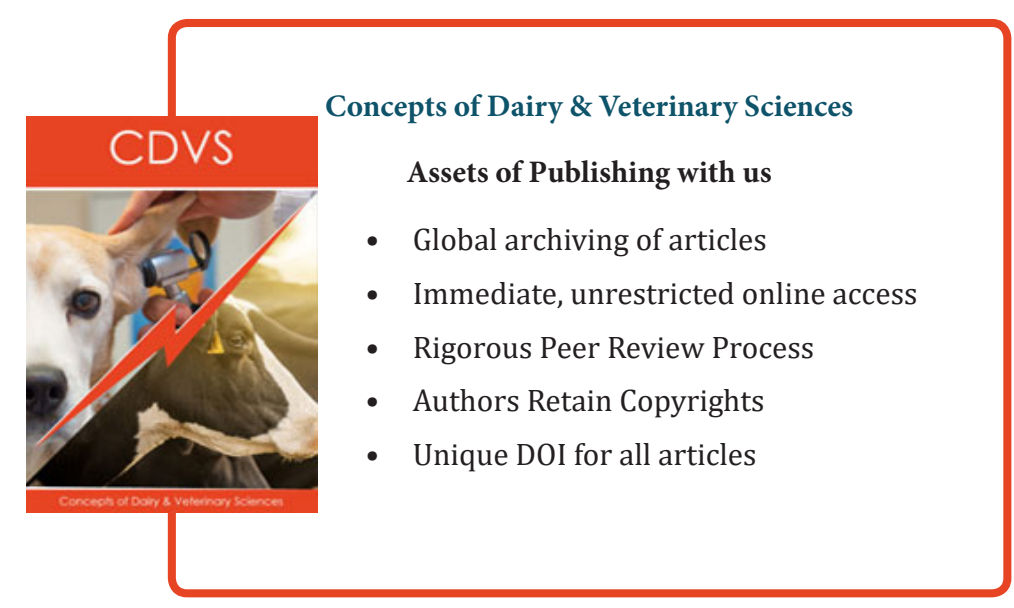

